\title{
DATING CHARRED REMAINS ON POTTERY AND ANALYZING FOOD HABITS IN THE EARLY NEOLITHIC PERIOD IN NORTHEAST ASIA
}

\author{
Dai Kunikita ${ }^{1,2} \bullet$ Igor Shevkomud $^{3} \bullet$ Kunio Yoshida $^{4} \bullet$ Shizuo Onuki $^{1} \bullet$ Toshiro Yamahara $^{5} \bullet$ \\ Hiroyuki Matsuzaki ${ }^{6}$
}

\begin{abstract}
This study reconstructs food habits through carbon and nitrogen isotope analysis, and $\mathrm{C} / \mathrm{N}$ analysis of charred residues inside pottery from Amur River sites in Russia (Goncharka 1 site, Novotroitskoe 10 site, Kondon 1 site) and in Hokkaido, Japan (Taisho 3 site, Yachiyo A site). We obtained dates from 12,330 to 7920 BP for these sites. There are major differences in the carbon and nitrogen isotope ratios between the Taisho 3 site $\left(\delta^{13} \mathrm{C}:-21.7\right.$ to $-24.1 \%$; $\left.\delta^{15} \mathrm{~N}: 11.9-14.7 \%\right)$ and the other sites $\left(\delta^{13} \mathrm{C}:-22.0\right.$ to $-27.1 \%$; $\delta^{15} \mathrm{~N}: 7.1-13.1 \%$ ), suggesting that the people of the Taisho 3 site made use of anadromous fish such as salmonids and some species of trout, as well as marine resources. The dates from the other sites except Taisho 3 were assumed to be from a mixture of marine foods, $C_{3}$ plants and terrestrial animals, and freshwater fish. The food boiled in the pots also indicated a high dependence on marine resources during the initial stages of the emergence of pottery.
\end{abstract}

\section{INTRODUCTION}

It is known that the region of Northeast Asia was the site of the world's earliest emergence of pottery $(\sim 15,000 \mathrm{cal}$ BP, as at the Odai Yamamoto 1 site in Japan; Nakamura et al. 2001). The precipitating factors for the emergence of pottery are believed to be related to ecological changes accompanied by climatic changes from the end of the Pleistocene to the early Holocene. Many theories have been proposed regarding the functions and uses of pottery in the early Neolithic in Northeast Asia on the basis of pottery shapes (capacity and type) and stone artifact composition, changes in the natural environment, the beginning of river fishing, and the use of nuts. Recent results show that pottery emerged in 3 regions of East Asia (south China, the Japanese Islands, and the Russian Far East), and it seems that the combination of environmental changes and the necessity of processing terrestrial plants and freshwater fish and mollusks resulted in the production of pottery-making in East Asia (Kuzmin 2010). The emergence of pottery was a groundbreaking event in prehistoric East Asia. Therefore, examining the process will be extremely valuable for understanding the subsequent years of the Neolithic period.

Some scholars have conducted various stable carbon and nitrogen isotope analyses of human bone collagen since the 2000s for reconstruction of food habits in the Neolithic period in Northeast Asia (Kuzmin et al. 2002). This technique can also apply to charcoal samples as a measurement indicator for determining the existence of the marine reservoir effect in the ${ }^{14} \mathrm{C}$ dating of charred residues found on pottery. Some interesting data were reported at the Goly Mys 1 site in Russia with the aim of reconstructing food habits (Sakamoto 2007). The Goly Mys 1 site $\left(52^{\circ} 09^{\prime} 08^{\prime \prime} \mathrm{N}, 140^{\circ} 00^{\prime} 65^{\prime \prime} \mathrm{E}\right)$ is located on the south coast of Lake Udyl', one of the lakes spreading over the lowlands on the north side of the Sikhote Alin Mountains, in the northeast lower Amur River basin. The charred remains on pottery from the Goly Mys 1 site are characterized by $\delta^{13} \mathrm{C}$ of -28 to $-25 \%$ and $\delta^{15} \mathrm{~N}>10 \%$. Judging from the $\delta^{13} \mathrm{C}$ value, they are unlikely to have been affected by the marine reservoir effect; however, the proposed age gives a date that is several hundred years older. Sakamoto (2007) points

\footnotetext{
${ }^{1}$ Faculty of Letters, The University of Tokyo, 7-3-1 Hongo, Bunkyo-ku Tokyo 113-0033, Japan.

${ }^{2}$ Corresponding author. Email: dkunikita@yahoo.co.jp.

${ }^{3}$ Museum of Archaeology, Khabarovsk Regional Museum after NI Grodekov, 86 Turgeneva st., Khabarovsk 680000, Russia.

${ }^{4}$ University Museum, The University of Tokyo, 7-3-1 Hongo, Bunkyo-ku Tokyo 113-0033, Japan.

${ }^{5}$ Obihiro Centennial City Museum, 2 Midorigaoka, Obihiro-shi Hokkaido 080-0846, Japan.

${ }^{6}$ School of Engineering, The University of Tokyo, 2-11-16 Yayoi, Bunkyo-ku Tokyo 113-0032, Japan.
}

(C) 2013 by the Arizona Board of Regents on behalf of the University of Arizona Proceedings of the 21st International Radiocarbon Conference edited by A J T Jull \& C Hatté RADIOCARBON, Vol 55, Nr 2-3, 2013, p 1334-1340 


\section{Kunikita et al.}

out the possibility of a freshwater reservoir effect. Sakamoto (2007) also reports dates of the Okhotsk culture. The Okhotsk culture is characterized as a hunter-gatherer type based on marine resources from the 5 th through the 9 th centuries.

To clarify a broad regional chronology of cultures and a transition in subsistence activities of groups in Northeast Asia, we measured ${ }^{14} \mathrm{C}$ dates from charred remains on pottery from Amur River sites in Russia (Goncharka 1 site, Novotroitskoe 10 site, Kondon 1 site) and Hokkaido sites in Japan (Taisho 3 site, Yachiyo A site) and reconstructed food habits of the early Neolithic period in the Russian Amur River basin and the Japanese island of Hokkaido. This article reports those results.

\section{MATERIALS AND METHODS}

Analyses were conducted on materials from 5 sites (Figure 1). Goncharka $1\left(48^{\circ} 19^{\prime} 18^{\prime \prime} \mathrm{N}\right.$, $\left.134^{\circ} 50^{\prime} 50^{\prime \prime} \mathrm{E}\right)$ and Novotroitskoe $10\left(48^{\circ} 19^{\prime} 45^{\prime \prime} \mathrm{N}, 134^{\circ} 51^{\prime} 46^{\prime \prime} \mathrm{E}\right)$ are located on a terrace on the right bank of the Amur River. The relative height of the terrace from the present river is about $16 \mathrm{~m}$. The Kondon 1 site $\left(51^{\circ} 16^{\prime} 02^{\prime \prime} \mathrm{N}, 136^{\circ} 34^{\prime} 35^{\prime \prime} \mathrm{E}\right)$ is located in the present-day Kondon village along the Khuin River, which runs into the Amur River. Although these sites are far from the sea, salmonids and some species of trout run up the Amur River to spawn. The Taisho 3 site $\left(42^{\circ} 48^{\prime} 45^{\prime \prime} \mathrm{N}\right.$, $\left.143^{\circ} 11^{\prime} 50^{\prime \prime} \mathrm{E}\right)$ and Yachiyo A site $\left(42^{\circ} 43^{\prime} 15^{\prime \prime} \mathrm{N}, 142^{\circ} 59^{\prime} 12^{\prime \prime} \mathrm{E}\right)$ are located in the southern area of the Tokachi Plain, Hokkaido, Japan. Taisho 3 is located on top of a terrace overlooking the Tobetsu River, a branch of the Tokachi River flowing across the plain, about $40 \mathrm{~km}$ from the Pacific Ocean. The Yachiyo A site is located at the southwest edge of the Tokachi Plain, several km from the Urikari River, which is confluent with the Satsunai River. It is assumed that salmonids and some species of trout run up these rivers.

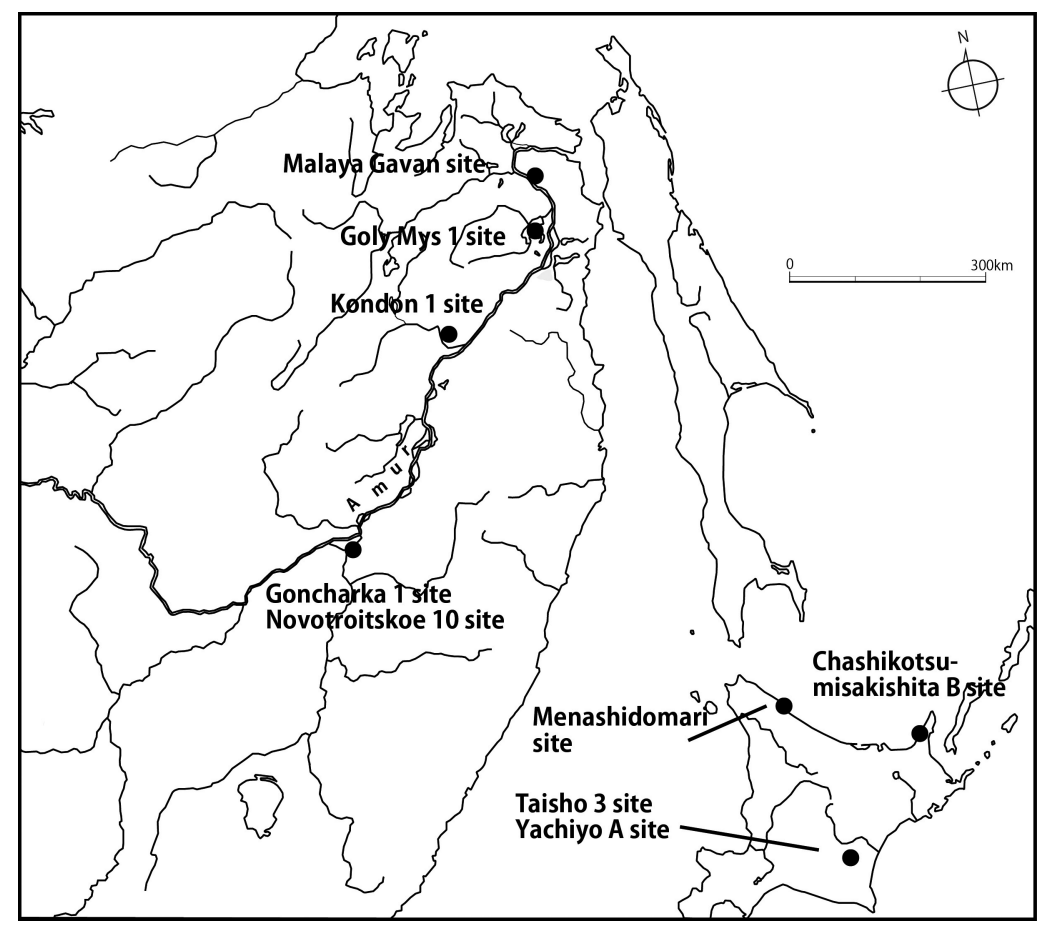

Figure 1 Map of Northeast Asia with location of the 5 sites in this study 
Dating Charred Remains on Pottery, Analyzing Food Habits

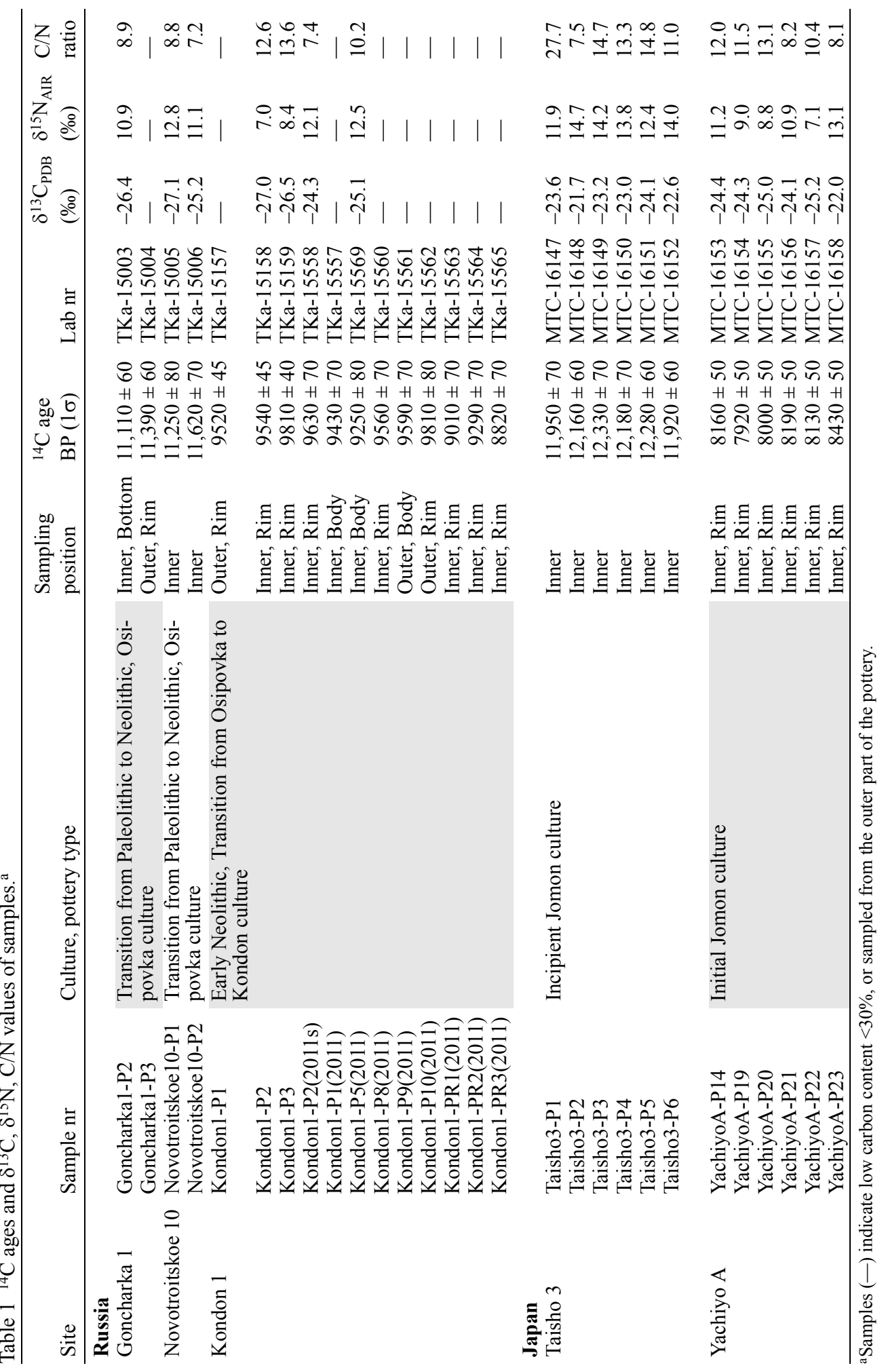




\section{Kunikita et al.}

Charred remains from the Kondon 1 site were excavated during the 2011 Japanese-Russian collaborative research. Those of the Novotroitskoe 10 site were collected during research in 2004, and the other remains from Goncharka 1, Taisho 3, and Yachiyo A have been stored at the Museum of Archaeology at the Khabarovsk State Regional Grodekov Museum in Russia and at Obihiro Centennial City Museum in Japan. The analysis included a total of 28 charred remains from pottery samples: 2 samples from Goncharka 1 ( 1 inner bottom, 1 outer rim); 2 samples from Novotroitskoe 10 ( 2 inner); 12 samples from Kondon 1 ( 7 inner rim, 2 inner body, 2 outer rim, 1 outer body); 6 samples from Taisho 3 (6 inner); 6 samples from Yachiyo A (6 inner rim) (Table 1).

Sample preparation for ${ }^{14} \mathrm{C}$ dating was done according to Yoshida et al. (2004). The concentration of the alkali treatment for the charred remains on pottery was kept to a level at which the test sample did not dissolve completely. The measurements were taken using the Micro Analysis Laboratory, Tandem accelerator (MALT) of the School of Engineering at the University of Tokyo. The C/N analysis of the carbon-nitrogen isotope ratio was conducted using an IsoPrimeEA stable isotope ratio mass spectrometer (Micromass, UK) at the Laboratory for Radiocarbon Dating in the Department of Research, University Museum, The University of Tokyo.

\section{RESULTS AND DISCUSSION}

\section{Radiocarbon Dating}

Table 1 presents the ${ }^{14} \mathrm{C}$ dates and carbon and nitrogen isotope ratios of the charred materials. Samples from the Goncharka 1 and Novotroitskoe 10 sites dated to the Paleolithic to Neolithic transition period, called the Osipovka culture in Far Eastern Russia, and samples from Taisho 3 were from the Incipient Jomon culture, which falls under the emergence stage of pottery in Japan. They resulted in dates of 12,330-11,110 BP. The oldest site from the emergence stage of pottery in Japan is Odai Yamamoto 1, which was reported to be $\sim 13,500$ BP $(\sim 15,000$ cal BP; Nakamura et al. 2001), whereas the ${ }^{14} \mathrm{C}$ dates obtained in this study were slightly younger in comparison. The Goncharka 1 site was dated to 12,500-9900 BP (Kuzmin 2006), and those dates are consistent with the dates in this study. The Kondon 1 samples are from the Early Neolithic, corresponding to the transition stage from the Osipovka to Kondon culture in Russia, while the Yachiyo A samples of the Initial Jomon culture in Japan gave ages of 9810-7920 BP. Although some scholars (e.g. Kuzmin 2006, 2012; Shevkomud and Kuzmin 2009) have undertaken aggregated overviews of ${ }^{14} \mathrm{C}$ dates in the Amur Basin and Primorye Province in Russia, there were few data from the Early Neolithic period in Russian areas. In those studies, Early Neolithic cultures are dated to 8585 BP (Suchu site) in the Lower Amur River Basin, and 8380 BP (Pereval site) in Primorye.

There are several problems with conducting research related to dating of artifacts in Northeast Asia. The first is that multiple cultural strata often exist at a site, and so there is no clear context for dating excavated charcoal. Another problem is that charred residues found on pottery within a clear context tend to be older than the true ages, due to marine and freshwater reservoir effects. The age gap between charred remains on pottery and wood charcoal was $\sim 400$ yr at the Ustinovka 8 site in Primorye Province (Kunikita et al. 2007), 310-575 BP at the Malaya Gavan site $\left(52^{\circ} 43^{\prime} 22^{\prime \prime} \mathrm{N}\right.$, $140^{\circ} 06^{\prime} 04^{\prime \prime} \mathrm{E}$ ) in the Amur River Basin (Kunikita et al. 2011), and 300-800 BP at the Chashikotsumisakishita B site in Hokkadio (Kunikita et al. 2006), suggesting marine and freshwater reservoir effects on the charred remains. The reporting of reservoir age, which reflects the past intensity of upwelling in these areas, has been inconsistent (Yoneda et al. 2001; Kuzmin et al. 2001). However, the carbon and nitrogen isotope ratios of charred residues found on pottery can be used to refine the archaeological chronology. In particular, charred residues on pottery with high values of both $\delta^{13} \mathrm{C}$ and $\delta^{15} \mathrm{~N}$ and a low $\mathrm{C} / \mathrm{N}$ ratio (Kunikita et al. 2007, 2011) could show older dates. However, the rela- 
tionships between $\delta^{13} \mathrm{C}, \delta^{15} \mathrm{~N}$, and ${ }^{14} \mathrm{C}$ dates of charred residues in these areas vary widely (300-800 $\mathrm{BP})$, so it is difficult to accurately recalibrate the ${ }^{14} \mathrm{C}$ dates using $\delta^{13} \mathrm{C}$ and $\delta^{15} \mathrm{~N}$ values of charred residues. We assume that the charred remains are derived exclusively from marine resources, mostly salmon and trout moving upstream. Therefore, samples from the Taisho 3 site and part of the Yachiyo A site (MTC-16158), which had a high distribution of both $\delta^{13} \mathrm{C}$ and $\delta^{15} \mathrm{~N}$, could be several hundred years older than the true ages.

\section{Food Habits Based on Isotope Analysis}

Figure 2 presents carbon and nitrogen isotope ratios and $\mathrm{C} / \mathrm{N}$ values of the charcoal found on the inner surfaces of pottery from the Goncharka 1, Novotroitskoe 10, Kondon 1, Taisho 3, and Yachiyo A sites, compared with the preceding data of the Middle to Late/Final Jomon and Okhotsk culture (Kudo et al. 2007; Kunikita et al. 2006; Kunikita and Yoshida 2011; Sakamoto 2007). In central Japan (Honshu Island), samples from the Shimoyakebe site in the Late to Final Jomon (Kudo et al. $2007, \delta^{13} \mathrm{C}$ : -22.6 to $26.5 \%$; $\delta^{15} \mathrm{~N}: 2.7-8.4 \%$ ) were found to be a mixture of marine and terrestrial animals, as well as fruits of terrestrial plants, whereas those at the Doudaira site in the Middle Jomon (Kunikita and Yoshida $2011, \delta^{13} \mathrm{C}-23.3$ to $-25.0 \%$; $\delta^{15} \mathrm{~N}$ : $0.5-6.4 \%$ ) were primarily terrestrial plants. In the Okhotsk Sea coast (Hokkaido Island), the Menashidomari site (Sakamoto 2007, $\delta^{13} \mathrm{C}$ : -21.8 to $23.6 \%$, $\delta^{15} \mathrm{~N} 12.2-17.6 \%$ ) and the Chashikotsumisakishita B site (Kunikita et al. 2006, $\delta^{13} \mathrm{C}$ : -22.0 to $-24.0 \%, \delta^{15} \mathrm{~N} 10.9-12.0 \%$ ) of the Okhotsk culture were primarily marine food. The Menashidomari $\left(45^{\circ} 02^{\prime} 30^{\prime \prime} \mathrm{N}, 142^{\circ} 30^{\prime} 20^{\prime \prime} \mathrm{E}\right)$ and Chashikotsumisakishita B sites $\left(43^{\circ} 53^{\prime} 36^{\prime \prime} \mathrm{N}\right.$, $143^{\circ} 35^{\prime} 33^{\prime \prime} \mathrm{E}$ ) are located on the low terrace front on the sea (Figure 1).

In the Hokkaido sites, the marine reservoir effect on the charred residues is clearly observed at each site. In the figure, the ovals mark the typical distribution of native food sources collected in the Japanese Archipelago and North Pacific (Yoshida and Nishida 2009). Samples from the outer surfaces of pottery and low carbon content $<30 \%$ were not measured for carbon and nitrogen isotope ratios. Such outer surface samples are not generally suitable for analyzing food habits because of soot caused by fuel and low carbon content that could be influenced by an impure ingredient in the pottery (i.e. clay and sediments). As shown in Figure 2, the carbon and nitrogen isotope ratios of the charred remains from all sites had a bit higher nitrogen distribution than that of the region covering $\mathrm{C}_{3}$ terrestrial animals. In particular, the results of the Taisho 3 site indicated high distribution of both $\delta^{13} \mathrm{C}$ and $\delta^{15} \mathrm{~N}$, which was quite different from the values from other sites. The $\mathrm{C} / \mathrm{N}$ values from the Taisho 3 site were lower than 15 values except for a single high value (MTC-16147). Since this sample had lower $\delta^{15} \mathrm{~N}$ than the rest, it may have had the influence of a mixture. There are no remarkable differences between the sites except Taisho 3 . The Okhotsk culture (5th-9th centuries) came from more northerly regions of Japan, and this culture had a high dependence on marine resources. Because of the analogy between the Taisho 3 site and the Okhotsk culture in Figure 2, food habits of this site are assumed to have had a higher dependency on marine resources, anadromous fish such as salmonids, and some species of trout. Meanwhile, the other sites except Taisho 3 site showed a bit higher nitrogen distribution than that of the region covering $\mathrm{C}_{3}$ terrestrial animals when compared with the Middle to Late/Final Jomon in Japan. Samples from the site are assumed to have a mixture of marine foods and $\mathrm{C}_{3}$ plants and terrestrial animals, and the dependence on marine foods was high compared to the Middle to Late/Final Jomon culture in Honshu Island. The ${ }^{14} \mathrm{C}$ dates of charred residues and wood charcoal in the Goly Mys 1 site in the Neolithic/Paleometal period (Koppi culture) were compared. The chronological age gap was around $400-540 \mathrm{BP}$, with $\delta^{13} \mathrm{C}:-24.9$ to $-28.6 \%$ and $\delta^{15} \mathrm{~N}$ : 9.2-12.7\% (Sakamoto 2007). Since the $\delta^{13} \mathrm{C}$ values tended to be primarily lower, this data may point to the possible use of some species of trout, resulting in a freshwater effect. The dates $\left(\delta^{13} \mathrm{C}-24.3\right.$ to $27.0 \% ; \delta^{15} \mathrm{~N}: 7.0-12.5 \%$ ) from the Kondon 1 site were similar to those from the 


\section{Kunikita et al.}

Goly Mys 1 site, and it may be possible that there was a higher dependency on freshwater fish rather than terrestrial mammals and plants. The dates from Goncharka 1, Novotroitskoe 10, and Kondon 1 sites were comparable to the results obtained from the previous research into the Middle to Late Neolithic period (Kunikita et al. 2011). Thus, it is believed that in the initial stages of the emergence of pottery in the Amur River basin, the food boiled in the pots was likely from the Early to Late Neolithic period.
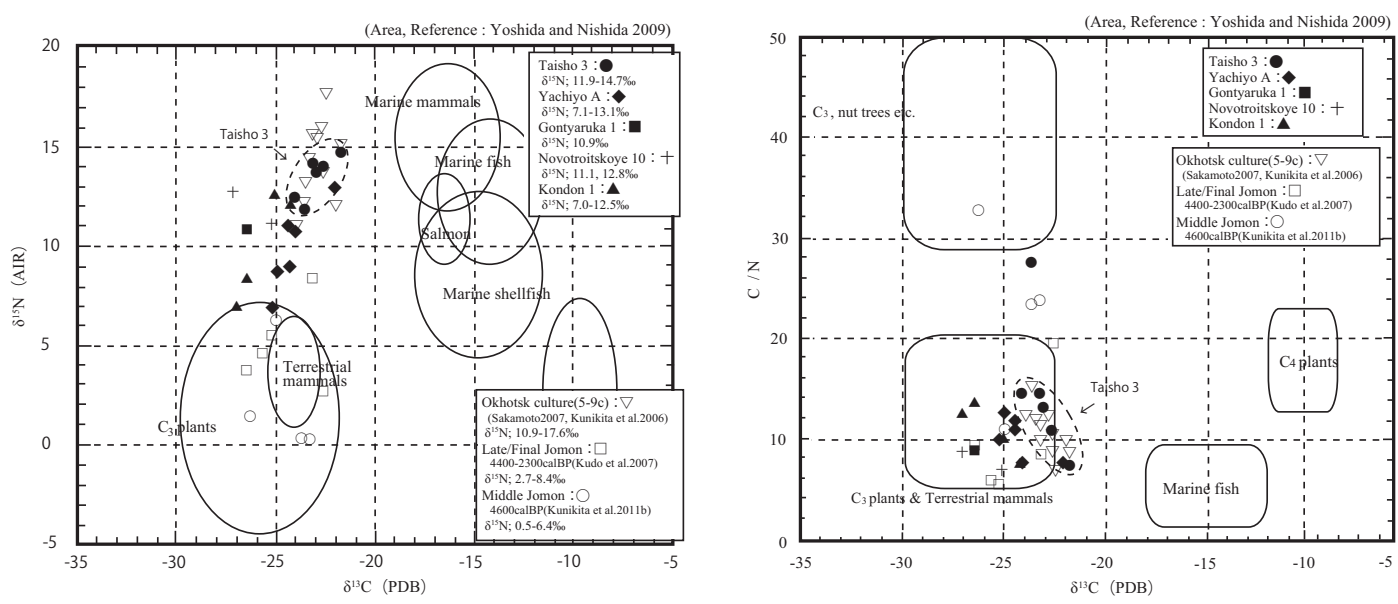

Figure 2 Carbon and nitrogen isotope ratios and $\mathrm{C} / \mathrm{N}$ values of the charcoal found on the inner surfaces of pottery from the sites in this study, compared with the data of preceding studies.

\section{CONCLUSION}

Charred remains inside pottery from Amur River sites in Russia (Goncharka 1, Novotroitskoe 10, Kondon 1) and sites in Hokkaido, Japan (Taisho 3, Yachiyo A) were ${ }^{14} \mathrm{C}$ dated to $12,330-7920$ BP. The dates of 12,330-11,110 BP for Goncharka 1, Novotroitskoe 10, and Taisho 3 correspond to the initial stages of the emergence of pottery. The dates of 9810-7920 BP for Kondon 1 and Yachiyo A correspond to the Early Neolithic and Initial Jomon periods.

There are major differences in the carbon and nitrogen isotope ratios and the $\mathrm{C} / \mathrm{N}$ ratios between the Taisho 3 site and the other sites, and the nitrogen ratio tends to be somewhat higher than that in domains with $\mathrm{C}_{3}$ plants and terrestrial animals. The charred samples from the Taisho 3 site tended to have a higher carbon isotope ratio, suggesting that the people ate anadromous fish such as salmonids and some species of trout, and marine resources. In the other sites, the tendency for a higher nitrogen ratio was observed (although lower than the dates of Taisho 3 ). These dates were assumed to result from a mixture of marine foods and $\mathrm{C}_{3}$ plants and terrestrial animals. According to previous research on the Goly Mys 1 site (Sakamoto 2007), the dates from Goncharka 1, Novotroitskoe 10, and Kondon 1 in the Amur River basin, which have a tendency toward slightly lower $\delta^{13} \mathrm{C}$ values, might record the possibility of freshwater fish with a freshwater effect rather than terrestrial mammals and plants. The food boiled in the pots also came mostly from marine foods and anadromous fish such as salmonids and some species of trout in the initial stages of the emergence of pottery, as at the Taisho 3 site. It is necessary to examine more sites in the future. 
Dating Charred Remains on Pottery, Analyzing Food Habits

\section{ACKNOWLEDGMENTS}

The authors would like to thank the staff of the Micro Analysis Laboratory, Tandem accelerator (MALT) and Radiocarbon Dating Laboratory, The University Museum, The University of Tokyo. This work was supported partly by the Grant-in-Aid for Scientific Research of the Japan Society of the Promotion of Science (JSPS) (subject \#: 07J04615, 19401030, 23720379, and 23251014).

\section{REFERENCES}

Kudo Y, Kobayashi K, Sakamoto M, Matsuzaki H. 2007. Toukyouto Shimoyakebe iseki ni okeru ${ }^{14} \mathrm{C}$ nendai kenkyu [A study on the radiocarbon ages in Shimoyakebe site, Tokyo]. Kokogaku Kenkyu 53(4):56-76.

Kunikita D, Yoshida K. 2011. Doudaira iseki syutudo siryo no ${ }^{14} \mathrm{C}$ nendai sokutei to tanso/tisso douitai bunseki [Radiocarbon dating and carbon and nitrogen analysis in the Doudaira site]. In: Doudaira iseki. Niigata: Tsunanmati Board of Education. p 393-401.

Kunikita D, Yoshida K, Miyazaki Y, Matsuzaki H. 2006. Hokkaido ni okeru dokifutyakubutsu to mokutan no nendaisa [Difference between radiocarbon ages of charcoal and charred remains on pottery in the Hokkaido Island, Japan]. The 9th Symposium of Japanese AMS Society Proceedings. Tokyo: The University of Tokyo. p 41-6. In Japanese with English abstract.

Kunikita D, Yoshida K, Miyazaki Y, Saito K, Endo A, Matsuzaki H, Ito S, Kobayashi T, Fujimoto T, Kuznetsov AM, Krupyanko AA, Tabarev AM. 2007. Analysis of radiocarbon dates of an archaeological site in the Russian Far East: the marine reservoir effect as seen on charred remains on pottery. Nuclear Instruments and Methods in Physics Research B 259(1): 467-73.

Kunikita D, Shevkomud IY, Yoshida K. 2011. Amuru karyuiki ni okeru shinsekkibunka hensen no nendaikenkyu to syokuseibunseki [A study on the periods of Neolithic cultural transition and an analysis of food habits in the lower reaches of the Amur River.] In: $A$ Study on the Formation and Transformation Process of Sedentary Food Gathering Society in Northeast Asia. Tokyo: The University of Tokyo. p 201-36. In Japanese with English summary.

Kuzmin YV. 2006. Palaeoenvironment and chronology. In: Nelson SM, Derevianko AP, Kuzmin YV, Bland RL, editors. Archaeology of the Russian Far East: Essays in Stone Age Prehistory. England: BAR International Series 1540. Oxford: Archaeopress. p 13-40.

Kuzmin YV. 2010. Radiocarbon chronology for prehistric complexes of the Russian Far East: 15 years later. Radiocarbon 54(3-4):727-36.

Kuzmin YV. 2012. The origin of pottery in East Asia and its relationship to environmental changes in the Late Glacial. Radiocarbon 52(2-3):415-20.

Kuzmin YV, Burr GS, Jull AJT. 2001. Radiocarbon reservoir correction ages in the Peter the Great Gulf, Sea of Japan, and eastern coast of the Kunashir, southern Kuriles (Northwestern Pacific). Radiocarbon 43(2A): 477-81.

Kuzmin YV, Richards MP, Yoneda M. 2002. Palaeodietary patterning and radiocarbon dating of Neolithic populations in the Primorye Province, Russian Far East. Ancient Biomolecules 4(2):53-8.

Nakamura T, Taniguchi Y, Tsuji S, Oda H. 2001. Radiocarbon dating of charred residues on the earliest pottery in Japan. Radiocarbon 43(2B):1129-38.

Sakamoto M. 2007. Tanso 14 nendaihou ni yoru Hokkaido/Roshia renpou shutsudo ibutsu no kousei nendai no kentou [Study of calibrated dates of artifacts in the Russia and Hokkaido by radiocarbon dating]. In: Usuki I, editor. Hokkaido ni okeru kodai kara kinsei no iseki no rekinendai. Hokkaido: Sapporo Gakuin University. p 7-31.

Shevkomud IY, Kuzmin YV. 2009. Khronologiya kamennogo veka Nizhnego Priamurya (Dalny Vostok Rossii) [Stone Age chronology of the Lower Amur River basin (Russian Far East)]. In: Shevkomud IY, editor. Kulturnaya Khronologiya i Drugie Problemy v Issledovaniyakh Drevnostei Vostoka Azii. Khabarovsk: Khabarovsky Kraevoi Muzei. p 7-46.

Yoneda M, Hirota M, Uchida M, Uzawa K, Tanaka A, Shibata Y, Morita M. 2001. Marine radiocarbon reservoir effect in the western North Pacific observed in archaeological fauna. Radiocarbon 43(2A):465-71.

Yoshida K, Nishida Y. 2009. Koukokagaku ga saguru kaendoki [Study of Kaen pottery by archaeological science]. In: Country of 'Kaen pottery'. Niigata: Niigata Prefectural Museum of History. p 87-99.

Yoshida K, Ohmichi J, Kinose M, Iijima H, Oono A, Abe N, Miyazaki Y, Matsuzaki H. 2004. The application of ${ }^{14} \mathrm{C}$ dating to potsherds of the Jomon period. Nuclear Instruments and Methods in Physics Research B 223224:716-22. 